\title{
Are we ready to battle against a new H1N1 pandemic?
}

The previous pandemic outbreak of $\mathrm{H} 1 \mathrm{~N} 1$ in 2009 was recorded as having a large number of severe cases which needed intensive care management amounting to around $9-31 \% .{ }^{1}$ It also had many fatalities approximating to $14 \%$ to $46 \%$ of severe cases. ${ }^{2} 25 \%$ of these incidences were reported from South East Asia ${ }^{1}$ leaving us with an obligation to manage the new pandemics more efficiently. The immediate causes for the fatalities reported were related to respiratory issues followed by cardiovascular events. ${ }^{2}$ With the experience of the 2009 pandemic many guidelines were put into practice. Out of these, the guidelines important for intensive care include the critical care management of severe forms of the disease and the use of ventilator strategies. They are not only important, but demand improvements as well. The nature of the rising trend of the death rate during the last episode in 2009 makes this compulsion more imperative. How much and up to what extent these recommendations are being used for the current ongoing outbreak, the changes suggested and the expected pitfalls need to be learnt and appraised. Hence as critical care specialists we should be well aware of the current management strategies.

The most significant hurdle for intensive care management was identified as management of severe ARDS in the category of $\mathrm{P} / \mathrm{F}$ ratio of $<100$ and circulatory failure. About $75 \%$ of these severe category patients were also reported to have underlying medical conditions.

\section{Revisiting the ventilatory management of severe ARDS ${ }^{3}$}

The use of Non Invasive Ventilation (NVI) is still debatable because of the reported risk of failure and delay in instituting invasive ventilation when it becomes mandatory. NIV should be limited to use only in the very early stages of ARDS. If the gas exchange parameters and the respiratory mechanics are not corrected, it needs to be changed into invasive ventilation without delay and we should be able to make this decision against the false sense of security.

High flow nasal cannula (HFNC) can be used to deliver humidified oxygen. High flow of 50L work by reducing the work of breathing and improving oxygenation and $\mathrm{CO}_{2}$ clearance and have shown good results. Worsening of gas exchange or haemodynamic instability or neurological deterioration will lead to the necessity of intubation and mechanical ventilation.

Mechanical ventilation in patients with severe ARDS should target adequate oxygenation and $\mathrm{CO}_{2}$ exchange and minimize the possibility of ventilator induced lung injury (VILI). The use of lung recruitment manoeuvers by sustained inflation of the alveoli by the increase in airway pressures for 20-40 seconds with the use PEEP is vital. During the last few years, the beneficial effects of PEEP have moved to a bigger scope other than as a lung protective strategy. This difference in opinion was imperative as wavering results were shown between the evident positive effects of use of higher PEEP values in some studies and no difference in outcome with the low values as in ALVEOLI, EXPRESS, and LOV studies. ${ }^{4.5}$,

There can be varying degrees of lung recruitability due to the presence of differing proportions of lung oedema. The estimation of oedema in the lung is best achieved by CT, which is the gold standard, or lung ultrasound scan. ${ }^{7}$ Surprisingly, when considering the relationship of lung recruitability and PEEP, it was found that the required PEEP was not related to the lung recruitability. ${ }^{7}$ This led to the justification that recruitability probably not only depended on the extent but the nature and the distribution of the oedema as well. This impression opened up the debate on the request of individualized or set PEEP based on some variable, either based on respiratory mechanics or by maintaining a set tidal volume. These valuations need a reliable estimation of the pleural pressures which can be done by the end expiratory absolute oesophageal pressures, but with ambiguity. ${ }^{8}$ Another more accurate PEEP setting was explained with the use of calculated end expiratory transpulmonary pressure which is rated as a better marker of lung compliance or lung stress. This uses the changes in the oesophageal pressure with the use of PEEP and set tidal volume which is individualized and in different combinations. ${ }^{9}$ Use of airway pressures alone can be misrepresentative as it can be affected by different transpulmonary pressures and pleural pressures. 


\section{Tidal volume}

It was well proven that the use of a tidal volume of $6 \mathrm{ml} / \mathrm{kg}$ of ideal body weight will not lead to VILI or hazardous stress on the lung but how correctly this is put to practice or how correct this statement is, is worth checking. One of the important factors to consider is, even though proven safe, the use of ideal body weight to calculate the tidal volume is found to be associated with misjudgment of the resting lung volume. Even the weight related tidal volumes can lead to different lung stresses. It is worth noting that the respiratory system compliance is related to the functional lung size and hence use of that as a variable is found to be more appropriate. The use of airway driving pressure which can be calculated as the ratio between the tidal volume and respiratory system compliance was suggested as a better method to determine functional tidal volume. ${ }^{10}$

\section{Mechanical ventilator modes}

Pressure controlled ventilation (PCV) or volume controlled ventilation (VCV) did not show to have differences in mortality or incidence of barotrauma. ${ }^{11}$ Some evidences were forwarded that assisted modes like neutrally adjusted ventilator assist (NAVA) provide a benefit for moderate ARDS. But we should bear in mind that assisted modes can increase transpulmonary pressure and work of breathing with rapid shallow breathing and still give rise to a possibility of VILI, Hence for severe ARDS the management is better with controlled modes.

This requirement also invites the discussion of the use of neuromuscular blocking agents (NMBA). NMBAs provides a positive remark when it comes to minimising the oxygen consumption and to facilitate the ventilator patient harmony while reducing the possibility of creating the build-up of negative intrapleural pressure which can increase lung stress. The downfall of this is the possibility of muscle weakness which can lead to delay in weaningfrom mechanical ventilation. Based on many studies the final remark can be spelt as NMBAs are necessary to manage severe ARDS in the acute phase but with daily reviews.

Regarding the gas exchange, the oxygenation aiming to a target saturation of $88-92 \%$ was accepted than a value of $>95 \%$. The hypercapnia resultant from advised low tidal volume can be accepted but will lead to a need of more NMBAs due to resultant high respiratory rate. The allowable hypercapnoea is reported as $70 \mathrm{mmHg}$ with a $\mathrm{pH} 7.2$, provided the absence of other conditions like raised intracranial pressure.

As a promising measure, prone positioning was evident with favourable results from recent metaanalysis. It showed 17 days of improved V/Q mismatch and better gas exchange. But it is also found that this needs to be reserved for patients with severe ARDS and also should not be included in the management of haemodynamically unstable patients. ECMO support is still looking forward with encouraging results to start and continue, specially in Sri Lankan set up.

Use of systemic corticosteroids were comprehensively debated and is reported to have no advantage and even lead to an increased risk of death. It is also being blamed for placing patients in a situation of acquiring hospital acquired pneumonia while failing to show concrete evidence as having benefit in H1N1 pneumonia. $^{12,13}$ There are some isolated case reports published in support of corticosteroids. ${ }^{14}$ Also on the other hand we should not forget the other side effects of steroids such as alteration of glycaemic control which have a negative effect on the recovery of critically ill patients. But in the meantime, in the same observational study, when adjusted for time dependent differences there were no significant relationship reported in corticosteroids and mortality ${ }^{15}$ leaving us in a dilemma due to the deficiencies of the methodology. Also, if the patient has other benefits of using steroids such as in COPD or adrenal insufficiency, the use is justified. ${ }^{16}$

Apart from implementing these strategies to improve the oxygenation and ventilation, patients need to be treated with a standard dose of oesltamivior (tamiflu) which needs a longer period than the usual 5 days. It is best to combine an antibiotic like third generation cephalosporin, quinolones, combined amphicillin/sulbactam or amoxicillin/clavulanate from the beginning with the antiviral.

There were many discussions about use of IVIG, statins and plasmapharesis but with no solid evidence of benefit. ${ }^{16}$

\section{Vasanti Pinto}

\section{Anuja Abayadeera}




\section{References}

1. Dawood FS, Iuliano AD, Reed C et al Estimated global mortality associated with the first 12 months of 2009 pandemic influenza A H1N1 virus circulation: a modelling study. Lancet Infect Dis 2012;12(9):687-95 https://doi.org/10.1016/S1473-3099(12)70121-4

2. Zhang Y, W Sun, ER Svendsen et al. Do corticosteroids reduce the mortality of influenza A (H1N1) infection? A meta-analysis. Crit Care 2015; 19:46

https://doi.org/10.1186/s13054-015-0764-5

PMid:25888424 PMCid:PMC4348153

3. Chiumello D, Brioni M. Severe hypoxemia: which strategy to choose. Critical Care 2016;20:132

https://doi.org/10.1186/s13054-016-1304-7

PMid:27255913 PMCid:PMC4891828

4. Brower RG, Lanken PN, MacIntyre $\mathrm{N}$ et al. Higher versus lower positive end-expiratory pressures in patients with the acute respiratory distress syndrome. N Engl J Med 2004; 351:32736.

https://doi.org/10.1056/NEJMoa032193

PMid:15269312

5. Briel M, Mead M, Mercat A et al. Higher vs lower positive end-expiratory pressure in patients with acute lung injury and acute respiratory distress syndrome: systematic review and meta-analysis. JAMA2010;303:865-73.

https://doi.org/10.1001/jama.2010.218

PMid:20197533

6. Bouhemad B, Brissen $\mathrm{H}$, Le-Guen $\mathrm{M}$ et al. Bedside ultrasound assessment of positive endexpiratory pressure-induced lung recruitment. Am J RespirCrit Care Med 2011;183(3):341-7. https://doi.org/10.1164/rccm.201003-03690C PMid:20851923

7. Cressoni M, Chiumello D, Carlesso E et al. Compressive forces and computed tomographyderived positive end-expiratory pressure in acute respiratory distress syndrome. Anesthesiology. 2014; 121(3):572-81. https://doi.org/10.1097/ALN.0000000000000373 PMid:25050573

8. Chiumello D, Cressoni M, Colombo A et al. The assessment of transpulmonary pressure in mechanically ventilated ARDS patients. Intensive CareMed2014;40(11):1670-8. https://doi.org/10.1007/s00134-014-3415-4 PMid:25112501

9. Chiumello D, Carlesso E, Cadringher $\mathrm{P}$ et al. Lung stress and strain during mechanical ventilation for acute respiratory distress syndrome. Am J Respir Crit Care Med 2008;178 (4):346-55.

https://doi.org/10.1164/rccm.200710-15890C PMid:18451319

10. Marcelo BP, Amato MD, Maureen $\mathrm{O}$ et al. Driving pressure and survival in the acute respiratory distress syndrome. N Engl J Med 2015;372:747-55.

https://doi.org/10.1056/NEJMsa1410639 PMid:25693014

11. Chacko B, Peter JV, Tharyan P et al. Pressurecontrolled versus volume-controlled ventilation for acute respiratory failure due to acute lung injury (ALI) or acute respiratory distress syndrome (ARDS). Cochrane Database Syst Rev. 2015;1:CD008807 https://doi.org/10.1002/14651858.cd008807.pub $\underline{2}$

12. Nedel WL, Nora DG, Salluh JIF et al. Corticosteroids for severe influenza pneumonia: A critical appraisal World J Crit Care Med 2016; 5(1): 89-95 https://doi.org/10.5492/wjccm.v5.i1.89 PMid:26855898 PMCid:PMC4733461

13. Matthay MA, Liu KD. Con: corticosteroids are not indicated for treatment of acute lung injury from H1N1 viral pneumonia. Am J RespirCrit Care Med 2011;183:1127-1128. https://doi.org/10.1164/rccm.201103-0395ED PMid:21531953 PMCid:PMC3114049

14. Djibré $\mathrm{M}$ et al. Non-invasive management of acute respiratory distress syndrome related to Influenza A (H1N1) virus pneumonia in a pregnant woman. Intensive Care Med. 2010;36:373-374.

https://doi.org/10.1007/s00134-009-1684-0 PMid:19820915

15. Delaney JW, Pinto R, Long J et al. The influence of corticosteroid treatment on the outcome of influenza A(H1N1pdm09)-related critical illness Critical Care 2016; 20(1):75 https://doi.org/10.1186/s13054-016-1230-8 PMid:27036638 PMCid:PMC4818504

16. Choi WS, Lee J, Lee HY et al. Severe influenza treatment guideline for Pandemic Influenza in Korea. Korean J Intern Med 2014; 29(1): 132147.

https://doi.org/10.3904/kjim.2014.29.1.132

PMid:24574848 PMCid:PMC3932389 